\title{
Exploring electroactive microenvironments in polymer-based nanocomposites to sensitize bacterial cells to low dose-embedded silver nanoparticles
}

Joana Moreira ${ }^{1,2}$, Margarida M. Fernandes ${ }^{1,2}$, Estela O. Carvalho ${ }^{1,2}$, Ana Nicolau ${ }^{2}$, Vesna Lazic $^{3}$, Jovan M. Nedeljkovic ${ }^{3}$ and Senentxu Lanceros-Mendez $z^{4,5}$

${ }^{1}$ Centre of Physics, University of Minho, Braga, 4710-057, Portugal

${ }^{2}$ Centre of Biological Engineering, University of Minho, Campus de Gualtar, Braga, 4710-

057, Portugal

${ }^{3}$ Vinča Institute of Nuclear Sciences, University of Belgrade, P.O. Box 522, 11001 Belgrade, Serbia

${ }^{4}$ BCMaterials, Basque Center for Materials, Applications and Nanostructures, UPV/EHU Science Park, 48940, Leioa, Spain

${ }^{5}$ Ikerbasque, Basque Foundation for Science, 48009, Bilbao, Spain

Keywords: electroactive polymers; electroactive microenvironments; silver nanoparticles, mechanical stimuli; antibacterial activity

\section{Abstract}

The search for alternative antimicrobial strategies capable of avoiding resistance mechanisms in bacteria are highly needed due to the alarming emergence of antimicrobial resistance. The application of physical stimuli as a mean of sensitizing bacteria for the action of antimicrobials on otherwise resistant bacteria or by allowing the action of low quantity of antimicrobials may be seen as a breakthrough for such purpose. This work proposes the development of antibacterial nanocomposites using the synergy between the electrically active microenvironments, created by a piezoelectric polymer (poly(vinylidene fluoride-cotrifluoroethylene) (PVDF-TrFE)), with green-synthesized silver nanoparticles (AgNPs). The electrical microenvironment is generated via mechanical stimulation of piezoelectric PVDFTrFE/AgNPs films using a lab-made mechanical bioreactor. The generated material's electrical response further translates to bacterial cells, namely Escherichia coli and Staphylococcus epidermidis which in combination with AgNPs and the specific morphological features of the 
material induce important antibacterial and antibiofilm activity. Both porous and non-porous PVDF composites have shown antibacterial characteristics when stimulated at a mechanical frequency of $4 \mathrm{~Hz}$ being the effect boosted when AgNPs were incorporated in the nanocomposite, reducing in more than $80 \%$ the S. epidermidis bacterial growth in planktonic and biofilm form. The electroactive environments sensitize the bacteria allowing the action of a low dose of AgNPs (1.96\% (w/w)). Importantly, the material did not compromise the viability of mammalian cells, thus being considered biocompatible. The piezoelectric stimulation of PVDF-based polymeric films may represent a breakthrough in the development of antibacterial coatings for devices used at hospital setting, taking advantage on the use of mechanical stimuli (pressure/touch) to exert antibacterial and antibiofilm activity.

\section{Introduction}

Hospital-acquired infections (HAIs) caused by microorganisms such as Staphylococcus aureus, Escherichia coli and Pseudomonas aeruginosa, are a common complication in hospitalized patients, being responsible for 110,000 deaths per year in all EU countries [1]. The numbers may now be higher if we consider the actual COVID-19 pandemic scenario, since COVID-19 patients possess an increased risk of cross-contamination [2], which increases the mortality risk. Accounting to this problem is also the emergence of antimicrobial resistance, considered one of the main public health challenges the world is facing, as a result of the persistent use, overuse and misuse of antibiotics $[3,4]$. In fact, the increase in spread of infections and reduction in the effectiveness of the existing industrial products highlights the need for new materials/coatings and strategies able to limit the spread of infectious microbes, not only in hospital environment but also in common public places.

Nanotechnology, with emphasis on the development of advanced multifunctional materials, is considered an efficient tool for addressing this problem [5]. Nano-sized metallic and semiconductor particles are of particular interest due to improved optical, catalytic, and 
antimicrobial properties in comparison to their respective bulk counterparts $[6,7]$. In this context, electrical conductivity, stability (chemical and catalytic), and antibacterial activity distinguish AgNPs among other metal nanostructures. Indeed, silver-based compounds have been extensively studied and has been FDA approved for obtaining antimicrobial materials and coatings for indwelling medical devices $[8,9]$.

Other strategies that are gaining increased attention are the use of electroactive polymers for controlling the adhesion and proliferation of bacteria. The sensibility of cells (both eukaryotic and prokaryotic) to electrically active environments has already been proven. They detect these physical stimuli and translate them into biological and biochemical responses [10]. This knowledge has been a valuable tool for the development of electroactive materials, mainly based on poly(vinylidene fluoride), PVDF, with specific surface characteristics to be applied in regenerative medicine [11], promoting the proliferation and adhesion of eukaryotic cells [1215] and recently for antimicrobial approaches, inducing either anti- or pro-microbial activities depending on the conditions applied $[16,17]$. These outcomes are achieved due to the fact that electroactive materials are able to create varying surface charges in the material, when mechanical stress is applied, not only acting passively in the body but also providing the appropriate environment to assist, promote or induce specific cellular responses $[15,18]$. Other electroactive materials such as polylactic acid (PLLA) [19], poly (lactic-co-glycolic acid) (PLGA)[20] and natural polymers such as silk [21] have also been applied for such purposes. Studies concerning the assistance of mechano-electrical stimulation for improvement of antimicrobial efficiency are scarce, and these studies have been mainly devoted to inducing bacterial growth [22, 23]. Recently, a potential mechanism of action for Escherichia coli (E. coli) mechano-electrical transduction has been suggested, proving that bacteria feel the surrounding environment similarly as eukaryotic cells. According to the literature, membrane depolarization, through the application of low-frequency voltage, increase the calcium flux in E. coli. As a consequence, "gates" across the cell membrane, can be opened, sensitizing the 
bacteria to antimicrobial compounds, which is a valuable point for innovative antimicrobial approaches, since it devoid the mechanisms of resistance in bacteria [24].

This work proposes the development of nanocomposites with mechano-electrical properties, composed of the highly piezoelectric polymer poly(vinylidene fluoride-co-fluoroethylene) (P(VDF-TrFE)) filled with green-synthesized AgNPs. The synergistic effect between the antimicrobial agent, AgNPs, and the electroactive material P(VDF-TrFE) in the form of porous and non-porous polymeric film, in the presence of a mechanical stimulus, was thus evaluated. This polymer exhibits the highest piezoelectric response among polymers, and it is processable in a variety of shapes and morphologies, including films, nanospheres, or three-dimensional scaffolds [25]. Different effects of the material on bacteria were studied, as follow: (i) at static conditions, i.e., without the mechanical stimulus and bearing in mind the single effect of the different morphologies related to microstructural differences, (ii) at dynamic conditions, i.e., evaluating the mechano-electrical effect, due to the use of a mechanical bioreactor, (iii) the biocidal effect of silver, and (iv) the synergistic effect between the mechano-electrical and biocidal effects to sensitize bacteria.

This work thus reports the development of electroactive antimicrobial surfaces that exhibit antimicrobial activity boosted when a mechanical stimuli is applied, based on the piezoelectric response of the materials. These strategies are a breakthrough if it is considered the necessity of hygienic surfaces, which respond to touch, pressure or vibrations and avoid the proliferation of bacteria.

\section{Experimental Section/Methods}

2.1 Materials: Silver nitrate $\left(\mathrm{AgNO}_{3}, 98 \%(\mathrm{w} / \mathrm{w})\right)$ was purchased from Sigma-Aldrich (Madrid, Spain). Dextran was lab-produced, by incubating the enzyme dextransucrase isolated from Leuconostoc mesenteroides T3 in sucrose, as described previously [26]. Poly(vinylidene fluoride-co-trifluoroethylene), P(VDF-TrFE), 70/30 was supplied by PiezoTech (Lyon, France). 
2.2 Synthesis of Silver Nanoparticles: Colloidal silver nanoparticles (AgNPs) were synthesized in an aqueous medium using $\mathrm{AgNO}_{3}$ and dextran as a reducing agent according to the method developed by Davidović et al. [27]. Briefly, $7 \mathrm{mg}$ of $\mathrm{AgNO}_{3}$ was added to $100 \mathrm{~mL}$ of a $0.06 \%$ (w/v) dextran aqueous solution at $\mathrm{pH}=9$. The $\mathrm{pH}$ was adjusted using concentrated $\mathrm{NaOH}$ solution. Then, the solution was kept at $60^{\circ} \mathrm{C}$ for $3 \mathrm{~h}$ under vigorous magnetic stirring.). Different concentrations of $\mathrm{AgNO}_{3}(0.2 \mathrm{M}, 0.4 \mathrm{M}$ and $0.8 \mathrm{M})$ and dextran $(0.03 \%, 0.06 \%$ and $0.12 \%(\mathrm{w} / \mathrm{V}))$ were respectively combined to obtain the colloidal AgNPs, using the same $\mathrm{AgNO}_{3}$ and dextran ratio.

2.3 Characterization of colloidal Silver Nanoparticles: The hydrodynamic size of colloidal AgNPs at $25{ }^{\circ} \mathrm{C}$ was measured by dynamic light scattering (DLS) using Zetasizer Nano (Malvern Nano ZS, Malvern, United Kingdom). Data were analyzed using the Malvern ZetaSizer DTS 7.01 software to calculate the average particle diameter. This equipment evaluates the movement of charged particles in an electric field through the Doppler effect, using the Laser Doppler electrophoresis. The colloidal stability of the AgNPs was evaluated by photon correlation spectroscopy (PCS) using Malvern Zetasizer NS at $25.0 \pm 0.1^{\circ} \mathrm{C}$ at $\mathrm{pH}$ 9, the $\mathrm{pH}$ at which the AgNPs synthesis occurred. The morphology of AgNPs samples was visualized by Scanning Electron Microscopy (SEM) using a NOVA Nano SEM 200 FEI (ThermoFisher Scientific, Massachusetts, EUA) equipment. For that purpose, samples of AgNPs were mounted on aluminium stubs using conductive carbon adhesive tape. Then, a 2 $\mathrm{nm}$ thick gold/palladium coating was sputtered, providing conductivity to the sample surface.

2.4 Processing of the polymer nanocomposites: Pristine $\mathrm{P}(\mathrm{VDF}-\mathrm{TrFE})$ films were prepared by dissolving the polymer under magnetic stirring in $\mathrm{N}, \mathrm{N}$-dimethylformamide (DMF) at a concentration of $15 \%(w / v)$, i.e at a weight ratio of 15/85 (P(VDF-TrFE)/DMF), Figure 1. 
A temperature of $30^{\circ} \mathrm{C}$ was applied for $15 \mathrm{~min}$ in order to prevent the formation of aggregates. The complete dissolution of the polymer occurred after approximately $2 \mathrm{~h}$, when a clear solution was obtained. The P(VDF-TrFE) solution was poured into a glass substrate and uniformly spread with an extender (doctor blade method). For the production of nonporous films [18], glass substrates were placed in an oven (P-Selecta), at $210{ }^{\circ} \mathrm{C}$ for $10 \mathrm{~min}$, allowing rapid evaporation of the solvent and polymer melting. On the other hand, to produce porous films [18], the solvent evaporation was carried out at room temperature for $72 \mathrm{~h}$.

The nanocomposites were further developed at concentrations of $15 \%(w / v)$ PVDF and $1.96 \%$ (w/w $\mathrm{w}_{\text {polymer }}$ ) of AgNPs and processed in the form of non-porous and porous nanocomposite films, as previously mentioned. s (Figure 1a). For the preparation of these polymer composite films with the AgNPs, the colloidal solution of AgNPs were previously dried in an oven at $80^{\circ} \mathrm{C}$ for several days to obtain AgNPs in powder. These AgNPs were further resuspended in DMF using an ultrasonic bath (FB15056, Fisherbrand, Massachsetts, EUA) for approximately 2 minutes to obtain a non-aggregated dispersion. The polymer was then added to the solution and the subsequent procedure followed the steps described above for the pristine polymer, to obtain porous and non-porous nanocomposite films.

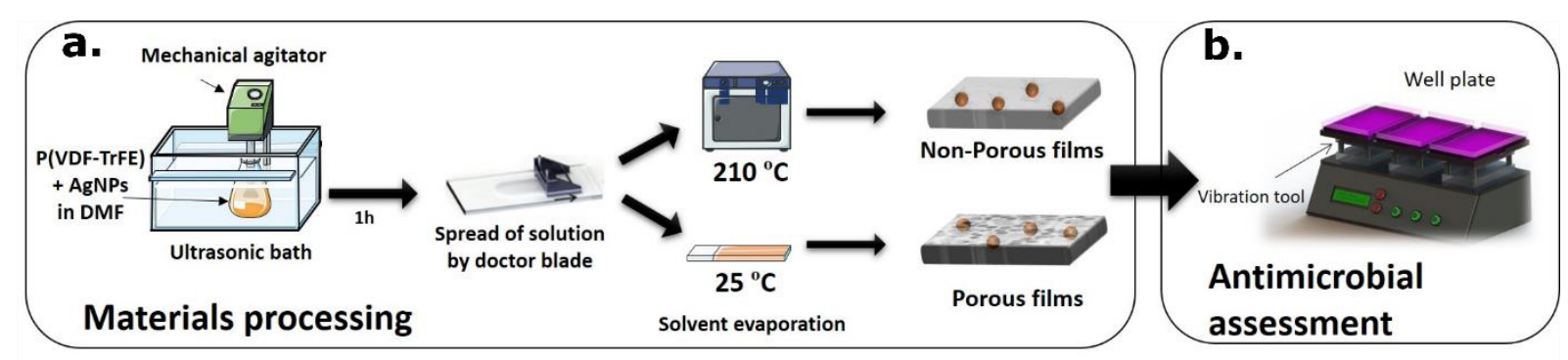

Figure 1. Schematic presentation of the (a) experimental procedure used for the preparation of composites by doctor blade method for obtaining porous and non-porous films and (b) bioreactor used for the dynamic stimulation of the piezoelectric film in the antimicrobial tests. 
2.5 Characterization of the polymer films: The morphology of the manufactured films was analysed by Scanning Electron Microscopy analysis using a NOVA Nano SEM 200 FEI, equipment after coating the samples with an approximatly $10 \mathrm{~nm}$ thick gold/palladium layer using a High Resolution Sputter Coater (208HR, Cressington, Liverpool, UK). This microscope operated at $10 \mathrm{kV}$, and samples viewed at a working distance of $8 \mathrm{~mm}$ and 10,000x magnification. The influence of AgNPs on the thermal behavior of P(VDF-TrFE) was assessed through Differential Scanning Calorimetry (DCS) and Thermogravimetric Analyzer (TGA) experiments. For DSC measurements, the samples were cut into small pieces of approximately $5 \mathrm{mg}$,and placed on aluminum pans. The measurements were carried out on a powercompensated DSC instrument (DSC-6000, Perkin Elmer,Massachusetts, EUA) under the nitrogen atmosphere. The aluminum pans were heated from 30 to $350{ }^{\circ} \mathrm{C}$ with a constant heating rate of $10^{\circ} \mathrm{C} \mathrm{min}^{-1}$. The degree of crystallinity $\left(\Delta \mathrm{X}_{\text {cryst }}\right)$ of the samples was calculated from the DSC scans using equation 1:

$$
\Delta \mathrm{X}_{\mathrm{cryst}}=\frac{\Delta H_{f}}{\Delta H_{100}}
$$

where $\Delta \mathrm{H}_{\mathrm{f}}$ is the melting enthalpy of the sample, and $\Delta \mathrm{H}_{100}\left(103.45 \mathrm{~J} \mathrm{~g}^{-1}\right)$ is the melting enthalpy of a $100 \%$ crystalline sample [28]. The weight loss measurements were performed using a TGA thermobalance (TGA 4000, Perkin Elmer, Massachusetts, EUA) in the temperature range from 30 to $600{ }^{\circ} \mathrm{C}$ under a nitrogen atmosphere. The heating rate was $20^{\circ} \mathrm{C} \mathrm{min}{ }^{-1}$, while the nitrogen flow rate was $20 \mathrm{~mL} \mathrm{~min}^{-1}$. The polymer phase was determined by Fourier Transform Infrared Spectroscopy (FTIR). The spectra from 650 to $4000 \mathrm{~cm}^{-1}$ were acquired at room temperature with a Spectrum Two spectrometer (Perkin Elmer, Massachusetts, EUA) coupled with a UATR (single refection diamond, Perkin Elmer) accessory. Results were obtained after collecting 64 scans with a resolution of $4 \mathrm{~cm}^{-1}$. 
2.6 Antimicrobial Assays: A Gram-negative Escherichia coli K12 and a Gram-positive Staphylococcus epidermidis NCTC 11047 were purchased from American Type Culture Collection (LGC Standards S.L.U.), and used in the bacterial assays. For the antimicrobial assays, the preparation of bacterial pre-inoculum was performed using a single colony from the corresponding stock bacterial culture, resuspending it in nutrient broth (NB) and then incubating overnight at $37^{\circ} \mathrm{C}$, and $110 \mathrm{rpm}$. After $16 \mathrm{~h}-20 \mathrm{~h}$, the optical density (OD) of $E$. coli and $S$. epidermidis cultures were measured at $600 \mathrm{~nm}$ and adjusted to $0.05 \pm 0.01$ in both cases, giving rise to a working inoculum of approximately $1 \times 10^{6}$ colony forming units $(\mathrm{CFU})$ per $\mathrm{mL}$.

2.6.1 Antimicrobial activity of AgNPs: Colloidal AgNPs antimicrobial activity was assessed using the microdilution antimicrobial assay. Different concentrations of AgNPs were prepared by serial dilutions of a $50 \%(\mathrm{v} / \mathrm{v})$ AgNPs stock colloidal solution in sterile NB using a 96-well microtiter plate. Each well of the microtiter plate was filled with $150 \mu \mathrm{L}$ of sterile NB and $150 \mu \mathrm{L}$ of AgNPs were introduced in the first row of the plate. Subsequently, a serial doubling dilution method was employed. The prepared microtiter plates were then inoculated with the bacteria, with each inoculum having approximately $1 \times 10^{6} \mathrm{CFU} \mathrm{mL} \mathrm{m}^{-1}$. Control wells were performed using the bacteria inoculum without any particles and the particles themselves without bacteria, to assess the optical interference of the NPs in the method. The plates were further sealed with a sterile adhesive sealer and incubated at $37{ }^{\circ} \mathrm{C}$ for $24 \mathrm{~h}$. The growth of bacteria was monitored using a microplate reader to measure the OD at $600 \mathrm{~nm}$, corrected for the absorbance of corresponding blanks, immediately, and after $24 \mathrm{~h}$. The results are presented in bacterial cell viability, which was calculated using equation 2, using as control the cells growing at the same conditions but without AgNPs:

Bacterial cell viability $(\%)=\frac{A b s_{600 \mathrm{~nm}} \text { sample }}{A b s_{6000 \mathrm{~nm}} \text { control }} \times 100$ 
2.6.2 Nanocomposites antimicrobial activity: The antimicrobial assays of the developed films were performed on nonporous and porous films with and without AgNPs. These were cut into $13 \mathrm{~mm}$ circles to fit a 24 well-plate and sterilized by exposure to ultraviolet light for 30 min, on each side. The working inoculum of E. coli and S. epidermidis were adjusted to an OD of $0.05 \pm 0.01$ at $600 \mathrm{~nm}$, corresponding to $1 \times 10^{6} \mathrm{CFU} \mathrm{mL} \mathrm{m}^{-1}$, and $250 \mu \mathrm{L}$ of the obtained bacterial suspension was placed in contact with the sterilized material on 24-well plates. Wells without any material were used as controls for bacterial growth. Under static condition, one well plate was placed in the incubator for $12 \mathrm{~h}$ at the temperature of $37^{\circ} \mathrm{C}$, without shaking or any other stimulus to bacteria. On the other side, under the dynamic conditions, the 24-well plate was placed on a lab-made bioreactor system [17, 29] with mechanical stimulation for 12 $\mathrm{h}$, also at $37{ }^{\circ} \mathrm{C}$ (Figure 1b). This stimulus corresponds to a vertical vibration module at a frequency of a $4 \mathrm{~Hz}$ with an amplitude of $1 \mathrm{~mm}$ [30]. This frequency was chosen in line with the knowledge that it creates specific charges in the surface of the material inducing antifouling properties [17] but can also induce cell death of an osteoblastic cell line (unpublished results). Two different methods were used to evaluate the antimicrobial properties of the film after overnight incubation: the Live/Dead kit that qualitatively evaluates the viable and non-viable bacteria adhered on the material surface and the optical density determination of the bacteria in suspension over the material. Bacterial adhesion was assessed by microscopy using the Live/Dead TM BacLightTM Bacterial Viability Kit (Invitrogen, US). After overnight incubation, the samples were washed with PBS $1 \mathrm{X}$ and then stained for $15 \mathrm{~min}$ in the absence of light with a mixture of $1.5 \mu \mathrm{L}$ green-fluorescent SYTO 9 and red-fluorescent propidium iodide [17]. Finally, the imaging of the samples was performed using a fluorescence microscope (Olympus BX51 microscope). The representative images were taken at a magnification of 40x. For assessing the antimicrobial activity in suspension, the OD of the bacteria inoculum in contact with the material for $12 \mathrm{~h}$ was measured at $600 \mathrm{~nm}$ and the bacteriostatic activity was 
assessed by applying equation (2), using as control the cells growing at the same conditions but without any material.

2.7 Cytotoxicity assessment: MC3T3-E1 preosteoblast cells obtained from Riken Bank (Missouri, EUA) were used in all cell tests. The cells were maintained in Dulbecco's modified Eagle's medium (DMEM, Gibco) containing $1 \mathrm{~g} \mathrm{~L}^{-1}$ glucose, $10 \%$ fetal bovine serum (FBS, Biochrom), and $1 \%$ penicillin/streptomycin $(\mathrm{P} / \mathrm{S}, \mathrm{Biochrom})$ in a controlled atmosphere at $37{ }^{\circ} \mathrm{C}$ and $5 \% \mathrm{CO}_{2}$. The culture medium was replaced every 2 days, and at pre-confluence, cells were harvested using trypsin-ethyl-enediaminetetraacetic acid (EDTA) (Biochrom, Massachusetts, USA).

2.7.1 Colloidal AgNPs cytotoxicity: Depending on the dose, AgNPs can be considered potential toxic components. To evaluate the possible adverse effects towards mammalian cells a direct contact assay with varying NPs concentration was performed.Similarly to what has been carried out for the antimicrobial tests, serial dilutions of a previously sterilized AgNPs solution at 50\% (v/v) in DMEM was performed using the serial doubling dilution method in a 96-well polystyrene tissue culture plate. The solutions were then placed in contact with previously seeded MC3T3-E1 pre-osteoblast cells. The cells were seeded at the density of $2 \times$ $10^{4}$ cells $\mathrm{mL}^{-1}$ in a 96-well tissue culture polystyrene plate and further incubated for $24 \mathrm{~h}$. The culture medium was removed from the plate and replaced with the previously diluted AgNPs and further tested for biocompatibility after $24 \mathrm{~h}$ incubation. The toxicity was then measured using the 3-(4,5-dimethylthiazol2-yl)-2,5-diphenyltetrazolium bromide (MTT) assay. This method evaluates the cell viability, measuring the mitochondrial activity of cells, which is an indirect assessment of the number of viable cells. Dimethylsulfoxide (DMSO, Sigma Aldrich) at a concentration of $20 \%(\mathrm{v} / \mathrm{V})$ in DMEM was used as positive control, while the cell culture medium was used as negative control. After $24 \mathrm{~h}$, the medium of every well was removed and $100 \mu \mathrm{L}$ MTT solution at a concentration of $10 \%(\mathrm{v} / \mathrm{V})$ in DMEM (stock solution of $5 \mathrm{mg} \cdot \mathrm{mL}^{-1}$ 
MTT in PBS) was added to each well. Viable cells convert MTT into a purple-colored formazan product, which after $2 \mathrm{~h}$ of incubation, may be measured by dissolving with DMSO the formed MTT crystals within the cells. The optical density was further measured at $570 \mathrm{~nm}$ using a spectrophotometric plate reader (Biotech Synergy HT). All quantitative results were obtained from five replicate samples and controls and analysed as the average of viability \pm standard deviation (SD), according to equation 3:

Cell viability $\operatorname{MTT}(\%)=\frac{A b s_{570 n m} \text { sample }}{A b s_{570 n m} \text { negative control }} \times 100$

2.7.2 Cell adhesion on the nanocomposites and materials biocompatibility: Cell adhesion studies were performed to assess the cytotoxicity of the films and to evaluate the cell adhesion on their surface. Circles with $11 \mathrm{~mm}$ were cut from each film, sterilized by exposure to ultraviolet light for 30 min on each side and placed on 48 -well tissue culture plate. Then a $35 \mu \mathrm{L}$ drop containing approximately $43 \times 10^{4}$ cell $\mathrm{mL}^{-1}$ of cells was placed on the surface of the material for 30 min to allow cell adhesion, and then $250 \mu \mathrm{L}$ DMEM was added to the well. The drop method was performed to avoid the seeding of the cells on the plate rather than on the material. After $24 \mathrm{~h}$ and $72 \mathrm{~h}$ the cells growing over the material were evaluated for their viability using a (3-(4,5-dimethylthiazol-2-yl)-5-(3-carboxymethoxyphenyl)-2-(4sulfophenyl)-2H-tetrazolium) (MTS) assay. Similar to MTT, the MTS assay is a colouring method that allows determining the cell viability and is based on the NADPH or NADP-assisted bioreduction in living cells. The cell viability (\%) was then calculated using equation 4 in relation to the negative control. i.e, cells growing in cell culture medium without any material. For evaluating the cell adhesion after $24 \mathrm{~h}$ incubation, two replicates of each film were washed with PBS 1x solution and fixed with $4 \%$ formaldehyde (Panreac) for 10 min at $37{ }^{\circ} \mathrm{C}$. The 
samples were later washed again with PBS $1 \mathrm{x}$ and incubated with a solution of $1 \mu \mathrm{g} \mathrm{mL}^{-1}$ phalloidin tetramethylrhodamine (TRITC, Sigma-Aldrich) for $45 \mathrm{~min}$ at room temperature. Thereafter, the samples were washed and incubated with $1 \mu \mathrm{g} \mathrm{mL} \mathrm{m}^{-1}$ of a 4,6-diamidino-2phenylindole (DAPI, Sigma-Aldrich) solution for 5 min. A final wash with PBS 1x was performed on all samples and visualized under fluorescence microscopy (Olympus BX51 Microscope). Representative images were obtained at a magnification of $40 \mathrm{X}$.

Cell viability $\operatorname{MTS}(\%)=\frac{A b s_{490 n m} \text { sample }}{A b s_{490 n m} \text { negative control }} \times 100$

2.8 Data Analysis. The results are presented as the average of individual measurements with the respective standard deviations and analyzed by GraphPad Prism Version 9.0.0 for windows (Graph Pad Software, San Diego, CA). To determine the statistical significance, one-way analysis of variance (ANOVA) was used, followed by the unpaired two-tailed Student's t-test method.

\section{Results and discussion}

\subsection{Silver nanoparticles synthesis and characterization}

The synthesized colloidal AgNPs were prepared by the reduction of the metal salt precursor, $\mathrm{AgNO}_{3}$, using dextran as a reducing agent. The preparation of these nanoparticles is environmentally friendly since no harsh chemicals were used for their synthesis. Instead, dextran was used, which ultimately acts as a stabilizing agent [31] able to render biocompatibility to the nanoparticles [27] (Figure 2a). Typically, the chemical reductions of $\mathrm{AgNO}_{3}$ is achieved using a variety of chemical agents, such as sodium borohydride, citrate, ascorbate, or elemental hydrogen [32], whose choice affects the size and shape of synthesized 
AgNPs. Sodium borohydride is the reductant that assists in the synthesis of monodispersed and small (less than $10 \mathrm{~nm}$ ) AgNPs. However, the use of such chemical agents is associated with biological hazards and environmental toxicity, so, to prevent that, natural polymers like chitosan, heparin, and dextrans have been increasingly used [33]. Dextrans are water-soluble polysaccharides with large molecules of glucose monomers with predominant $\alpha-1,6$ linkages, forming long linear chains. By adding sodium hydroxide to the aqueous medium, deprotonation of the hydroxyl group in dextran takes place, which induces the formation of AgNPs and its coordination to the surface of nanoparticles [31] (Figure 2a).

The spectrophotometric analysis of dextran-capped AgNPs reveals the presence of the surface plasmon resonance (SPR) band, usually located in the range 405-425 nm [31-33], obtained by the UV-Vis absorption spectrum of the silver colloid (Figure 2c). The appearance of yellow colour, observed during the synthesis, and the SPR band peak at $415 \mathrm{~nm}$ implies the effective interaction between nanometer-sized dextran-capped AgNPs with light, thus indicating the successful synthesis of the AgNPs [34]. The microscopic characterization of the nanoparticles further revealed that they are spherical in shape (Figure 2b) with a mean diameter of approximately $270 \mathrm{~nm}$, and a polydispersity index of 0.235 , as measured by DLS, denoting a polydisperse nature. This factor, however, does not influence their further incorporation into the polymer matrix for the envisaged application.

Although it is well-known that AgNPs are antimicrobial agents, the herein generated NPs are capped with dextran, which could eventually diminish their antibacterial activity. Two bacterial strains were assayed, E. coli and S. epidermidis (Figure 2d). Based on the obtained results, it is evidenced that the AgNPs can induce a successful bacteriostatic activity in the concentration range from 6 to $12.5 \%(\mathrm{v} / \mathrm{v})$, completely inhibiting bacteria growth after $24 \mathrm{~h}$ of incubation period. The S. epidermidis is slightly more susceptible to the AgNPs than E. coli, most probably due to their differences at the structural levels. Gram-positive bacteria have a thick cell wall (20-80 nm) with exposed the peptidoglycan layer to the surrounding environment, while, on the 
contrary, Gram-negative bacteria have a relatively thin cell wall $(<10 \mathrm{~nm})$ that is encased by another protective outer membrane [17]. The most accepted mechanism of toxic action of silver involves the interaction with the peptidoglycan layers, and, consequently, the higher sensibility of Gram-positive bacteria towards AgNPs. Accumulation of AgNPs on the surface of the bacterial membrane, followed with their penetration into the bacteria, changes the permeability of the bacterial membrane and causes its substantial damage [35]. Also, it is suggested that the antimicrobial behavior of silver can be a consequence of the release of $\mathrm{Ag}^{+}$, and the formation of reactive oxygen species (ROS) [36]. All the above-mentioned toxic mechanisms of silver propose cell damage to bacteria, as well as to mammalian cells. Therefore, it is of importance to assess the concentrations of AgNPs at which they are toxic and to estimate the concentration window when their application is safe. Cytotoxicity assay, performed using pre-osteoblasts, showed that the herein synthesized AgNPs are safe to apply at a concentration below $12.5 \%$ (v/v), concentration at which the cell viability is maintained above $70 \%$ after $24 \mathrm{~h}$ contact with the particles, indicating that it does not cause cell damage to mammalian cells (Figure 2e). 

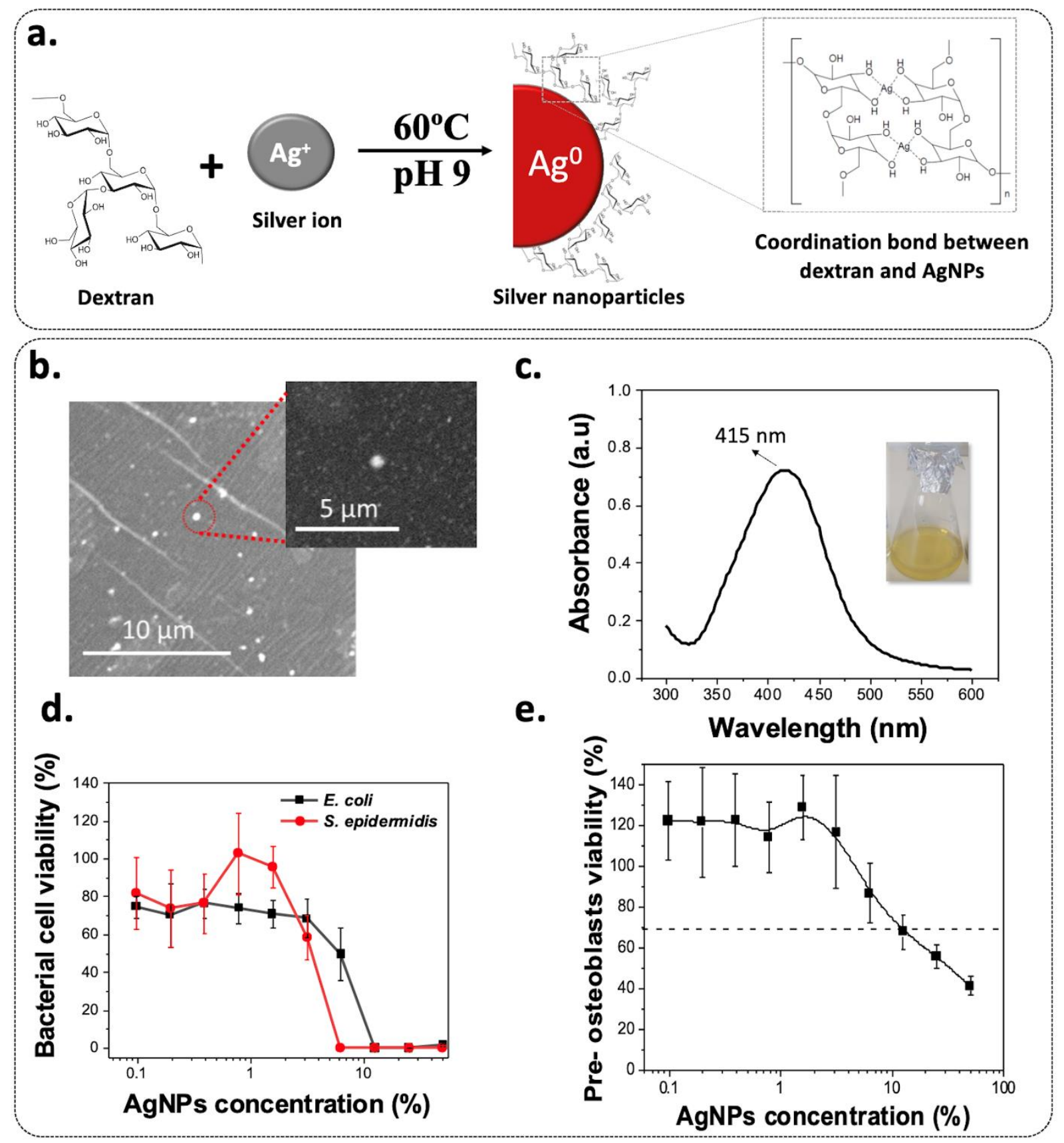

Figure 2. (a) Schematic presentation of the mechanism of colloidal AgNPs synthesis and the coordination bond formed between dextran molecules and silver nanoparticles. Characterization of colloidal AgNPs: (b) Representative SEM image of AgNPs, (c) UV-VIS spectrum of silver colloid and corresponding yellowed colour solution, (d) antimicrobial assay for the evaluation of the bacteriostatic activity of $E$. coli and $S$. epidermidis, and (e) biocompatibility assay of AgNPs towards MCT3-E1 pre-osteoblasts cells. The percentage of colloidal solution tested in (d) and (e) are in \% (v/v), in which $50 \%(\mathrm{v} / \mathrm{v})$ correspond to a concentration of $0.86 \mathrm{mg} / \mathrm{mL}$ of AgNPs. 


\subsection{Electroactive Nanocomposites Processing and Physico-Chemical Characterization}

The synthesized AgNPs were then incorporated into the $\mathrm{P}(\mathrm{VDF}-\mathrm{TrFE})$ polymer matrix to develop electroactive polymer-based nanocomposites. Nanocomposite films with two different morphologies, porous and non-porous, were prepared to study the influence of the microstructure on the antimicrobial activity of the material (Figure 1). It is expected that smooth surfaces may inhibit the adhesion of bacteria onto the surface [37] while the porous material may promote better interaction with the AgNPs, based to the larger surface area and access to the interior of the membranes, in the case of the AgNPs well incorporated in the interior of the films rather than on the surface.

Figure 3 shows representative SEM images of the prepared films; the upper panel shows the porous films with and without AgNPs, while the lower panel shows the non-porous films. The condition for obtaining such morphologies depends on the temperature at which the crystallization of the polymer takes place.[18] When the polymer crystallizes by cooling to room temperature after solvent evaporation and polymer melting at $210{ }^{\circ} \mathrm{C}$, a non-porous film is obtained (Figure 3f-i). However, by preparing the film by room temperature $\left(25^{\circ} \mathrm{C}\right)$ solvent evaporation, a phase liquid-liquid polymer-solvent phase separation occurs previous to solvent evaporation, inducing the formation of a porous microstructure (Figure 3a-d) [18]. The pores are particularly evidenced in the interior of the scaffold, showing also the pore interconnectivity (Figure 3a,c) [18]. The inclusion of the AgNPs does not influence the overall structure of the materials and nanoparticles are mainly present at the surface, as demonstrated by the white dots in the porous films (Figure 3d), corresponding to the AgNPs proven by the energy-dispersive X-ray spectroscopy (EDS) technique (Figure 3e). When the crystallization of the polymer takes place after melting at $210{ }^{\circ} \mathrm{C}$, the AgNPs agglomerate, forming wire-like structures at the polymer surface (Figure 3i); the presence of silver is also confirmed by the EDS technique (Figure 3j). In fact, similar approaches have been used to form nanowires from nanoparticles 


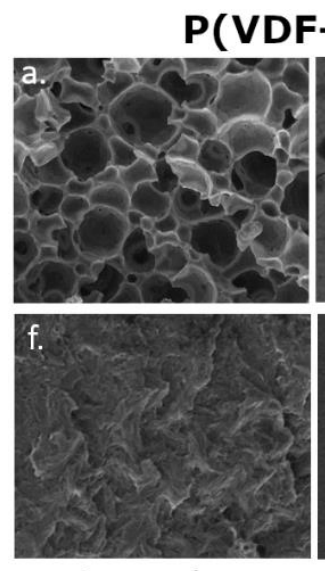

Cross section
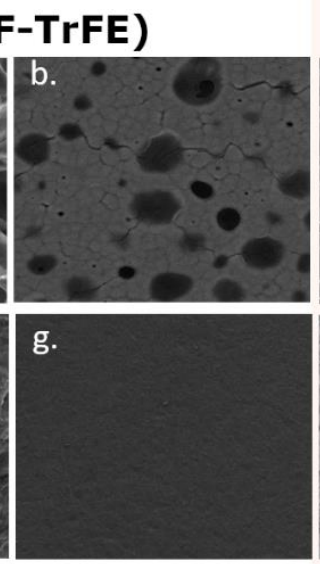

Surface

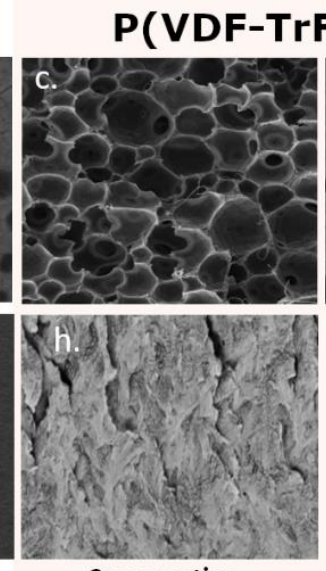

Cross section
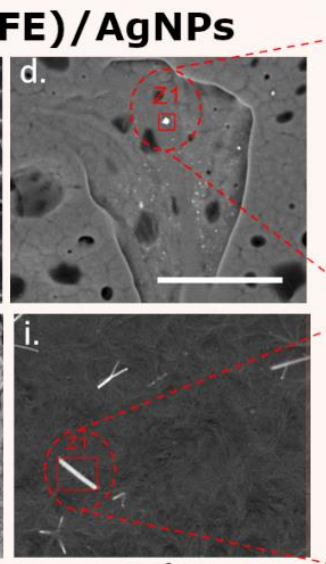

Surface
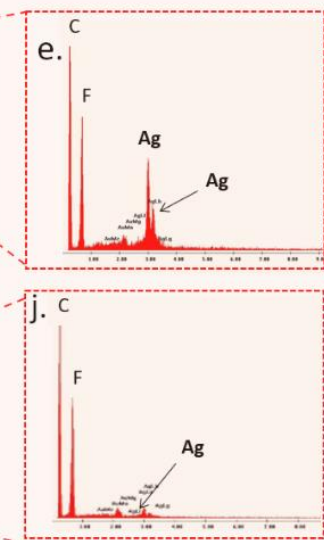

EDS

Figure 3. SEM images representing the developed $\mathrm{P}(\mathrm{VDF}-\mathrm{TrFE})$ films and respective EDS. $\mathrm{P}(\mathrm{VDF}-\mathrm{TrFE})$ and $\mathrm{P}(\mathrm{VDF}-\mathrm{TrFE}) / \mathrm{AgNPs}$ cross-section and surface images of the samples prepared by solvent evaporation at $25^{\circ} \mathrm{C}$ (a-d) and after polymer melting at $210^{\circ} \mathrm{C}(\mathbf{f}-\mathbf{i})$; EDS spectroscopic images of silver containing films that prove the presence of silver (e and $\mathbf{j})$. The scale bar represents $50 \mu \mathrm{m}$ for all images.

The ATR-FTIR spectra of the porous and non-porous $\mathrm{P}(\mathrm{VDF}-\mathrm{TrFE})$ nanocomposites filled with AgNPs are shown in Figure 4a. The observed absorption bands mainly correspond to the polymer. For example, the typical band at $840 \mathrm{~cm}^{-1}$, assigned to the electroactive $\beta$-phase of the polymer, is present in all samples, showing that the presence of the AgNPs did not influence the electroactive properties of the film The crystallization of P(VDF-TrFE) in the selected copolymer ration always occurs in the ferroelectric $\beta$-crystalline phase, independently of the processing conditions, contrary to PVDF. The crystallization of the co-polymer in the $\beta$-phase 
is a consequence of the presence of fluoride ions in the TrFE monomers that induces a steric hindrance in the polymeric structure and favors the all-trans conformation [40]. However, small differences between the ATR-FTIR spectra of porous and non-porous films are present. The non-porous films display only the typical vibration at $840 \mathrm{~cm}^{-1}$, while the additional bands at 766 and $1234 \mathrm{~cm}^{-1}$, observed in porous films, belong to the $\alpha$-phase and $\gamma$-phase of PVDF, respectively, showing that the formation of $\alpha$ - and $\gamma$-phase in $\mathrm{P}(\mathrm{VDF}-\mathrm{TrFE})$ is induced.

The determination of the thermal stability of the composites is a prerequisite for the determination of their applicability. Also, evaluation of the thermal properties combined with infrared data provides the possibility to assess the crystallinity of the material and to corroborate the identification of the crystalline phases. The DSC thermograms of all samples (Figure 4b) display the presence of two endothermic peaks. The first peak (labeled $\mathrm{T}_{\mathrm{fp}}$ ), at a lower temperature, corresponds to the ferroelectric-paraelectric phase transition, while the second peak (labeled $\mathrm{T}_{\mathrm{m}}$ ) represents the melting temperature [41]. Differences between thermograms of porous and non-porous samples are small, similar to the observed ones in the infrared measurements. The $\mathrm{T}_{\mathrm{fp}}$ peak in the porous films appears at $102{ }^{\circ} \mathrm{C}$, while in the case of nonporous films is slightly shifted to higher temperatures $\left(107^{\circ} \mathrm{C}\right)$. The $\mathrm{T}_{\mathrm{fp}}$ peak identifies the ferroelectric-paraelectric phase transition and its position depends on the crystalline structure and morphology of the films [28]. The incorporation of Ag NPs into the polymer matrix did not alter the overall thermal behavior of the samples.

The degree of crystallinity in the prepared samples was calculated using equation 3 , and the obtained data are presented in Figure 4c. The crystallinity of the films slightly increases with the presence of AgNPs either in the form of porous and non-porous films, as small amounts of nanofillers act as nucleating agents for crystallization in the crystallization process [42].

The TGA and corresponding DTG curves of the prepared samples, obtained under the atmosphere of nitrogen, are shown in Figure 4d. There is an overlap of the obtained thermogravimetric curves, indicating that there are no relevant differences in thermal behavior of the 
samples. The degradation of polymers occurs in one step, mainly in the temperature range 400$500{ }^{\circ} \mathrm{C}$ [43], as indicated by a single peak at about $450^{\circ} \mathrm{C}$ in TGA curves. The presence of $\mathrm{Ag}$ NPs does not affect the degradation process of polymer, although at the high-temperature end of TGA curves $\left(700^{\circ} \mathrm{C}\right)$ slightly lower percentage of weight loss is observed.

a.

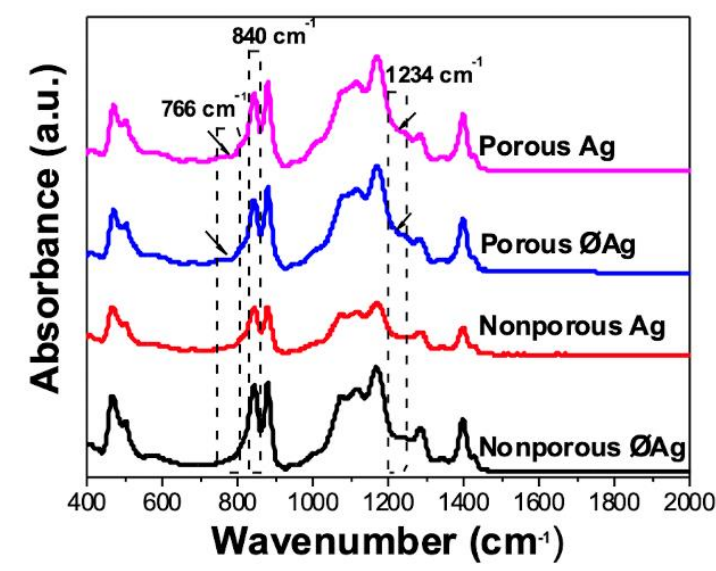

c.

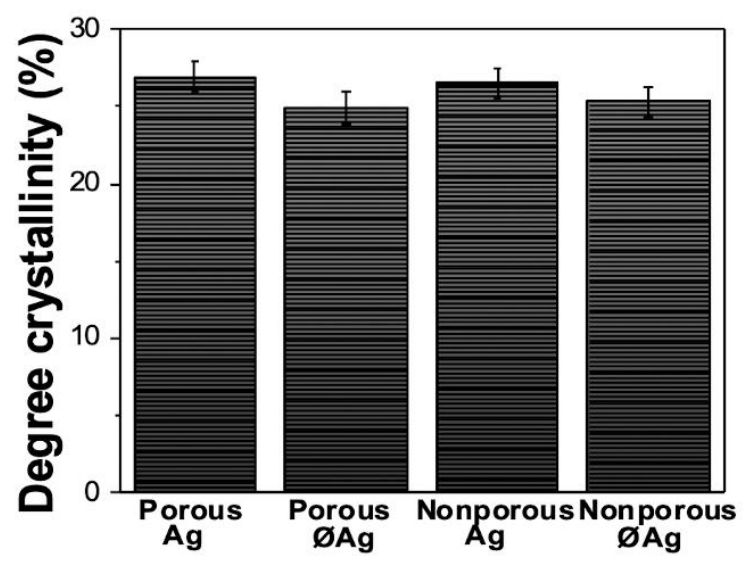

b.

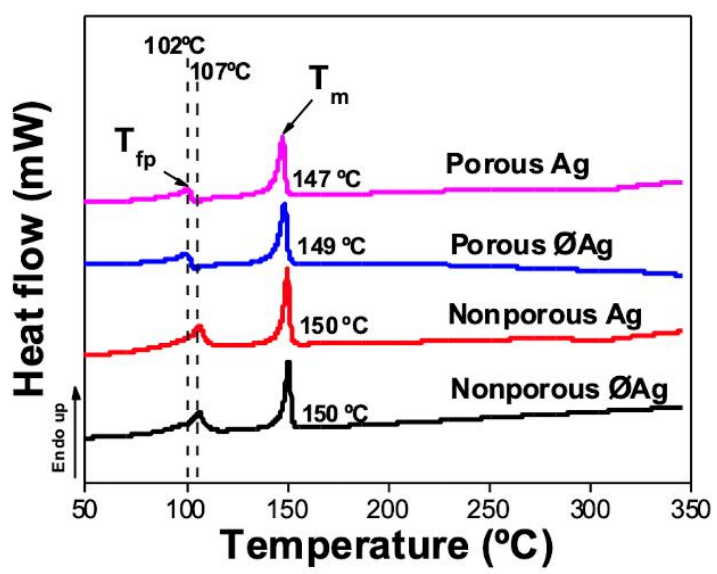

d.

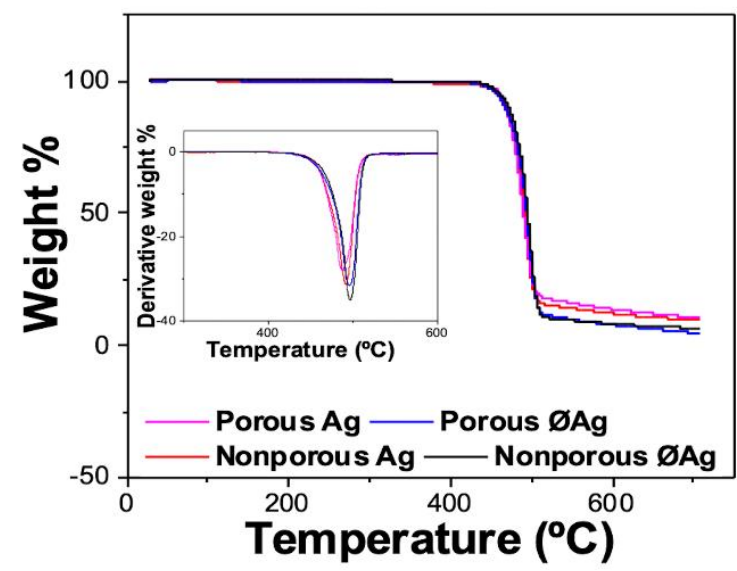

Figure 4. Characterization of the $\mathrm{P}(\mathrm{VDF}-\mathrm{TrFE})$ porous and non-porous nanocomposites with (Ag) and without (ØAg) AgNPs: (a) FTIR-ATR spectra, (b) DSC curves, (c) degree of crystallinity, and (d) TGA and corresponding DTG (inset) curves.

\subsection{Antimicrobial Activity Assessment at Static and Dynamic Conditions}

To evaluate whether the synergism between the AgNPs and the electroactive polymer, when mechanically stimulated, leads to improved antimicrobial activity and to what extent, the 
biological responses of Gram-positive E. coli and Gram-negative S. epidermidis bacteria were evaluated.

Experiments were performed using samples with different morphologies (porous and nonporous films) prepared with and without AgNPs, as well as experiments with and without application of the piezoelectric stimuli, i.e., under dynamic and static mechanical stimulation, respectively. Dynamic conditions indicate a varying mechanical cue in the piezoelectric material, through the use of a mechanical bioreactor (Figure 1b) placed below the material, generates a varying electrical stimulus to the bacterial cells [17]. These electroactive microenvironments are achieved by mechanically stimulating electroactive polymers such as PVDF-based ones taking advantage of their piezoelectric properties, an approach that is being increasingly explored for tissue engineering applications [29, 44, 45].

After overnight incubation with and without the mechanical cues, applied on the piezoelectric films, it is observed that $E$. coli are only slightly influenced by the applied stimuli since there are no significant differences between the samples (Figure 5b). Only a minor decrease in bacteria viability is observable when the bacteria grew over the non-porous material containing silver, as expected, due to the well-known bactericidal effect of silver (Figure 5b). Also, it is worth mentioning that in the other herein studied materials, a proliferation effect is observed instead, indicating a piezoelectric-mediated proliferation effect, which may be associated with the fast growth induced by the applied stimuli, as previously observed [17]. These results may suggest that the mechano-electric stimuli favorably assist this process, through the event of membrane depolarization that induces an increased influx of calcium ions and results in higher proliferation rates [24]. According to the literature, a mechano-electric stimulation, such as the one occurring in this study, induces the proliferation of the mammalian cells pre-osteoblasts [15].

On the other side, in the case of S. epidermidis, an antimicrobial effect is observed when the stimuli are applied. When this Gram-positive bacteria experience a piezoelectric effect at the 
frequency of $4 \mathrm{~Hz}$, their growth is significantly inhibited (Figure 5a), in a similar way to what has been observed by Carvalho et al. when such frequencies were applied [17]. Gram-positive bacteria thus seem to be more sensitive to the stimuli, which may be related to the structural composition of their cellular membrane. These differences in the cell membrane confer different properties to the cell, producing different responses to external stimuli, like the ones applied in this study [46]. The inhibition effect may be due to the electrical polarization induced on the piezoelectric material by the mechanical cue that interacts with the exposed peptidoglycan layer of Gram-positive bacteria, probably leading to the rupture of the membrane through inactivation of the enzyme necessary for bacteria division [17].

The presence of AgNPs affected the bacteriostatic effect on both types of bacteria, Gram-positive and Gram-negative, at all conditions. The comparison of the films, prepared with and without silver, indicates the influence of the Ag NPs on the bacterial cell viability (Figure 5). Also, a synergistic effect between the electroactive environment, created by the mechanoelectrical, and the Ag NPs is clearly noticeable in the case of S. epidermidis. A sharp decrease in the bacteria viability is present when they grow over Ag containing films, subjected to the mechanical cue. This event is responsible for the inhibition of cellular growth and suggests that a potent antimicrobial effect is present in this assay.

At the material's morphology level, cell viability is always higher on porous films in both types of bacteria (Gram-positive and Gram-negative), indicating that bacteria prefer porous surfaces to trigger their growth. That is expected, because bacteria prefer rough, nonsmooth surface, to attach and proliferate [47-49]. Further, porous membranes show a larger surface area to the bacteria. The reason for using porous films was to promote effective interaction with the Ag NPs, present in the interior of the material, and to inhibit bacterial growth. However, this effect is not observed in E. coli and S. epidermidis, clearly indicating that for antimicrobial purposes, the non-porous films are a better choice. 
a.

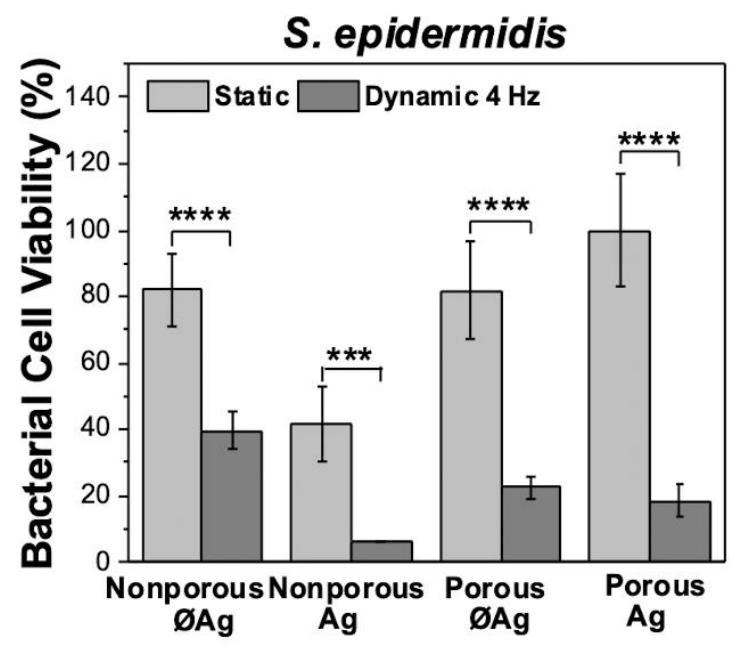

b.

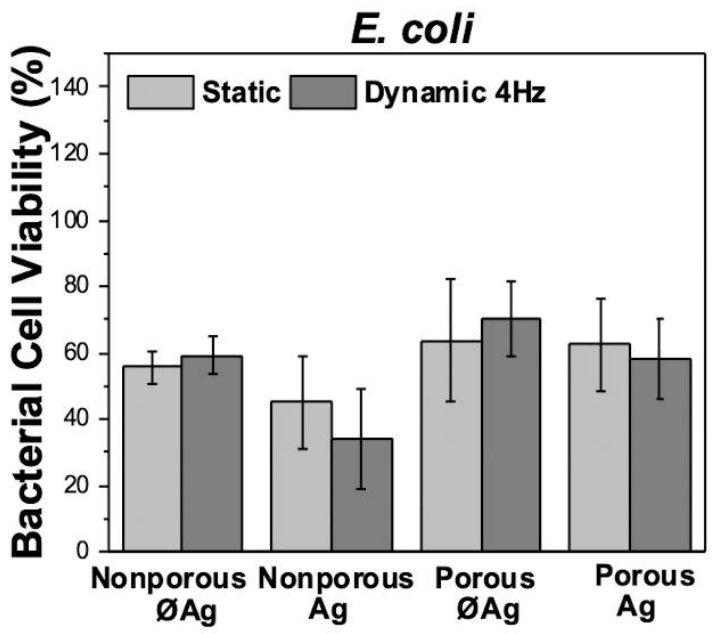

Figure 5. Bacteriostatic activity cell of S. epidermidis (a) and E. coli (b) in solution after overnight incubation over the material in static and dynamic conditions, the later by applying a mechanical cue on the piezoelectric material using a mechanical vibration frequency of $4 \mathrm{~Hz}$. The calculated percentage of bacterial cell viability is related to the control cell of cells growing at the same conditions but without the material or stimuli. The results are the mean of three independent assays. ${ }^{* * *} P<0.0001$ and ${ }^{* * *} P<0.002$ static vs dynamic conditions.

In Figure 6, Live/Dead fluorescent images of S. epidermidis and E. coli are shown, respectively, where green fluorescent cells are viable, whereas red fluorescent cells have compromised cell membranes. The effects observed on the surface of the material are in good agreement with those of bacteria in solution, presented in Figure 5.

At static conditions, S. epidermidis and E. coli adhere to the surface of P(VDF-TrFE) films and form a biofilm (Figure 6), a mechanism of defence that bacteria use when the nutrients from the solution settle in the surface, such as in the case of static conditions [49]. The presence of the mechano-electrical stimuli induces a decrease in bacterial growth and in biofilm formation most probably due to the electrical microenvironment which helps in the generation of a nutrient-poor solution, already proven by Carvalho et al. [17], which induce a bacteriostatic 
activity as well as antifouling properties to the surface of the material [49]. The effect of the AgNPs is also clearly visualized by the presence of a large number of compromised cells (red cells) either at static or dynamic conditions. Indeed, the presence of biofilm is smaller in comparison to the images obtained without AgNPs. Further application of mechanical stimuli on the $\mathrm{P}(\mathrm{VDF}-\mathrm{TrFE}) / \mathrm{AgNPs}$ piezoelectric materials, induce even higher numbers of compromised cells and even less biofilm formation. These images prove the possibility to tailor bacterial growth inhibition and antibiofilm activity due to the synergistic effect between the AgNPs and electroactive microenvironments.

In terms of material's morphology, the trend is similar to both tested bacteria and the non-porous smooth surface seems to better influence the antimicrobial activity of the material, mainly when both AgNPs and electroactive microenvironments are present. On the surface of the material, bacterial adhesion is more favourable in porous films. In fact, it is expected that porous films more easily promote biofilm formation, suggesting that the nutrients necessary for bacterial growth, are accumulated inside the pores, where the bacterial cells may easily accumulate as well. 


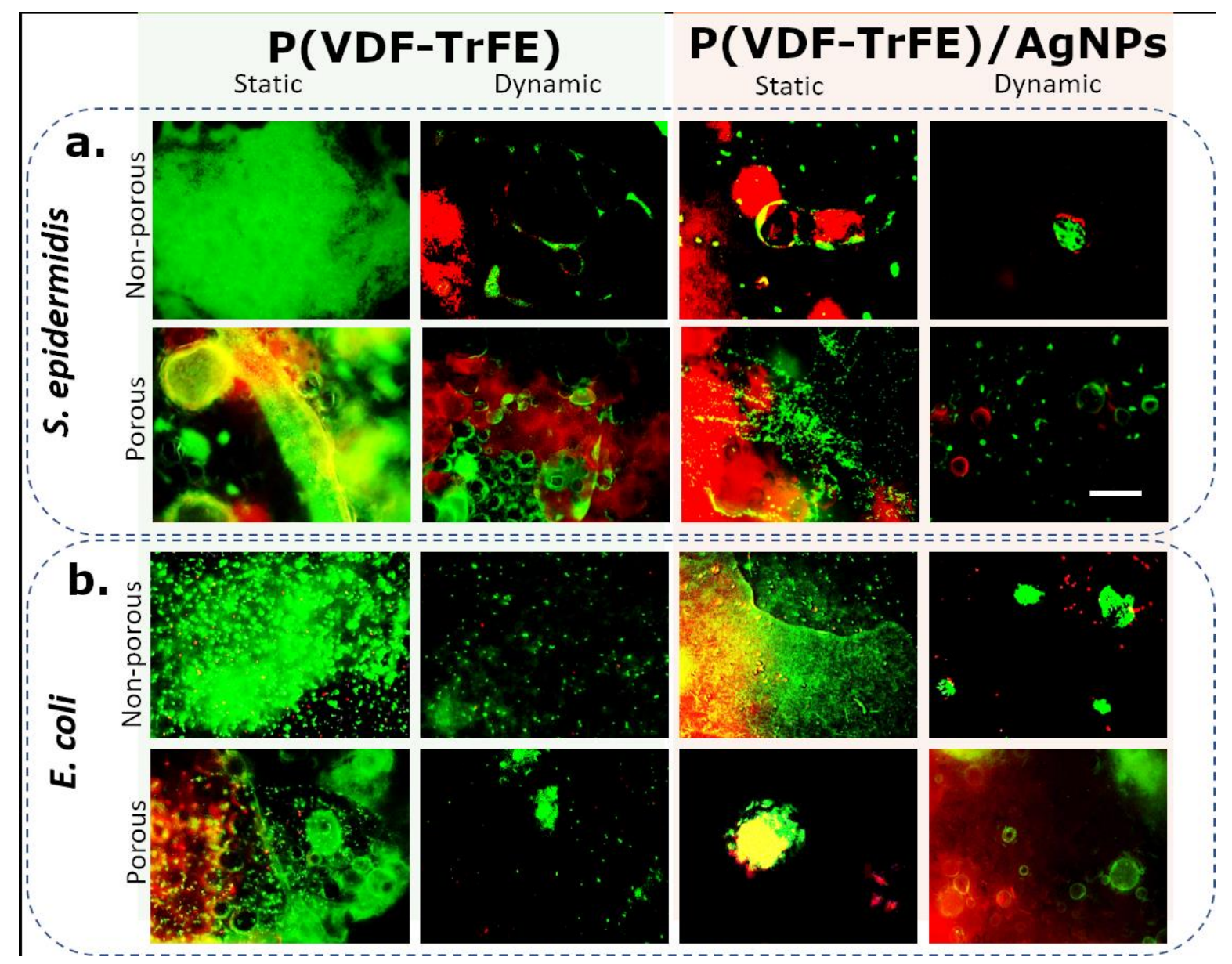

Figure 6. Fluorescence microscopy Live/Dead images of (a) S. epidermidis and (b) E. coli on different material surfaces after $12 \mathrm{~h}$ of incubation. Scale bar represents $20 \mu \mathrm{m}$ for all images.

\subsection{Biocompatibility assessment of the films}

Similarly to what occurs with the AgNPs, it is also important to assess the putative cytotoxicity of the developed materials in order to explore their use in the biological field. The metabolic activity of MC3TE-E1 pre-osteoblasts was evaluated with MTS assay at 24 and $72 \mathrm{~h}$ time points. Figure 7a show the cell viability of a cell culture on porous and non-porous P(VDFTrFE) films and on porous and non-porous $\mathrm{P}(\mathrm{VDF}-\mathrm{TrFE}) / \mathrm{AgNPs}$ composite films. Thus, the effects of introducing AgNPs in different morphologies/microstructures were analyzed. $\mathrm{P}(\mathrm{VDF}-\mathrm{TrFE})$ is a non-toxic biomaterial, already reported in several studies with the MC3T3- 
E1 pre-osteoblast cell line.[15, 50, 51] AgNPs, on the other hand, are considered a potential cytotoxic compound.[52]

Figure 7a shows viability of cells growing directly over the nanocomposite. Nonporous $\mathrm{P}(\mathrm{VDF}-\mathrm{TrFE}) / \mathrm{AgNPs}$ films induced certain toxicity to the cells growing over the surface, less than $70 \%$ of cell viability at $24 \mathrm{~h}$ was observed, which should be considered cytotoxic, according to the ISO standard 10993-5. On the other hand, the remaining films were found to be biocompatible. Nevertheless, at $72 \mathrm{~h}$, the cells growing over the nonporous P(VDFTrFE)/AgNPs composites films recover considerably which indicates that cells recover and no toxicity is observed. Usually, in the composite films, AgNPs are encapsulated by the polymer, preventing the risk of cytotoxic effects from the particles themselves. $\mathrm{P}(\mathrm{VDF}-\mathrm{TrFE})$ is a nonbiodegradable polymer, thus there is also little risk of particles leaching out from the films. It is possible that in the nonporous films, due to the smooth surface, the AgNPs protrude and aggregate at the surface (see Figure 3) thus inducing certain leaching and thus toxicity. Since the toxicity improves after $72 \mathrm{~h}$ it is acceptable to assume that the AgNPs do not leach anymore, which makes the cells recover and a biocompatible behavior is observed.

Moreover, cell adhesion study with MC3TE-E1 cell line was performed by visualizing the morphology of adhered cells under fluorescence microscopy, stained with DAPI and TRITC to color the cells nuclei and cytoskeleton, respectively. The results show that, in contrast to nonporous films featuring clean images (Figure 7b,d), porous ones disperse fluorescent light, leading to a background and therefore making analysis more difficult (Figure 7c,e). Furthermore, cells can also penetrate the pores, resulting in cells in different planes and thus contributing to blurred images. The cytoskeletons (red) in porous films appear to be smaller. This is likely due to cells entering the pores of the surface, which hinder the observation of cell elongation and orientation.

None of the images shown in Figure 7b-e exhibits significant differences in the number of nucleus present, i.e. cell density. It can then be concluded indirectly that the presence of 
nanoparticles (AgNPs) does not influence cell adhesion. The same is true for the different material morphologies, since there is no difference in cell density in porous and non-porous films.

As noted, there is a substantial difference between the measured cell viability of the nonporous $\mathrm{P}(\mathrm{VDF}-\mathrm{TrFE}) / \mathrm{AgNPs}$ composites sample (Figure 7a) and the others. This is not the case with immunofluorescence staining images, where no significant differences are observed. Nevertheless, these facts are consistent with cell viability measurements at $72 \mathrm{~h}$, corroborating that nonporous $\mathrm{P}(\mathrm{VDF}-\mathrm{TrFE}) / \mathrm{AgNPs}$ composites are, in fact, non-cytotoxic.

Thus, these results demonstrate the potential for the use of $\mathrm{P}(\mathrm{VDF}-\mathrm{TrFE}) / \mathrm{AgNPs}$ piezoelectric composites in biological applications, such as bone tissue engineering, which would also benefit from the fact that osteoblastic cells would be stimulated by the same mechano-electrical cue, as already proven before.[15, 50, 51] The combination of both antimicrobial effect and osteoblasts proliferation could constitute a breakthrough to overcome the bone-associated indwelling medical devices infections, since bone itself is piezoelectric and naturally generates the electroactive microenvironment upon movement.[53] 


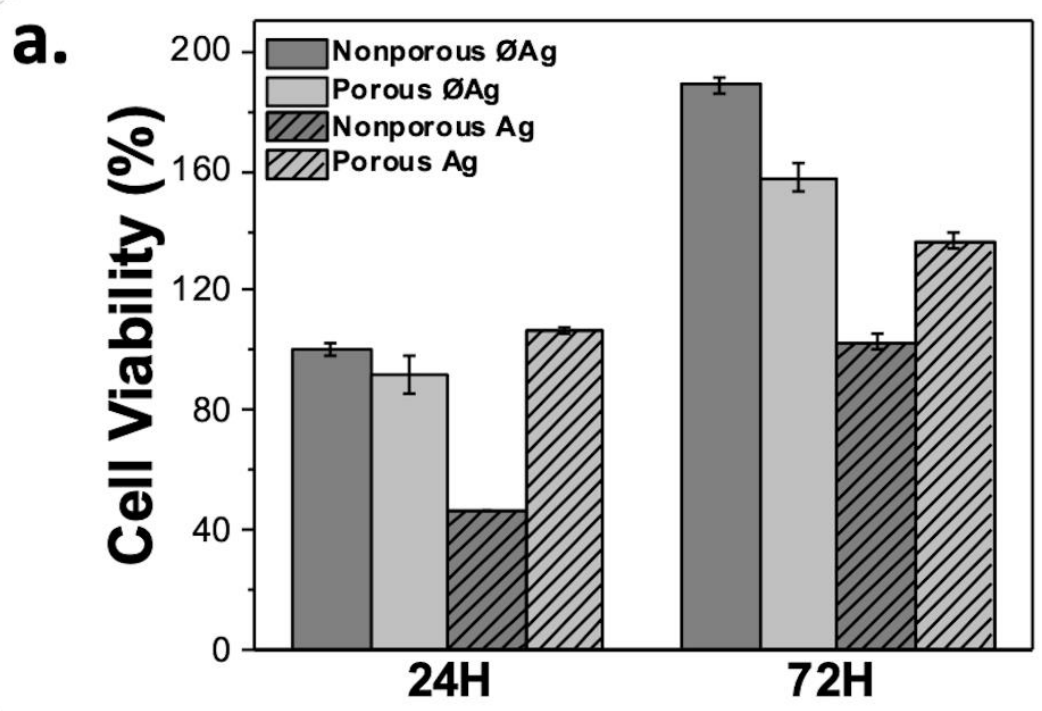

P(VDF-TrFE)
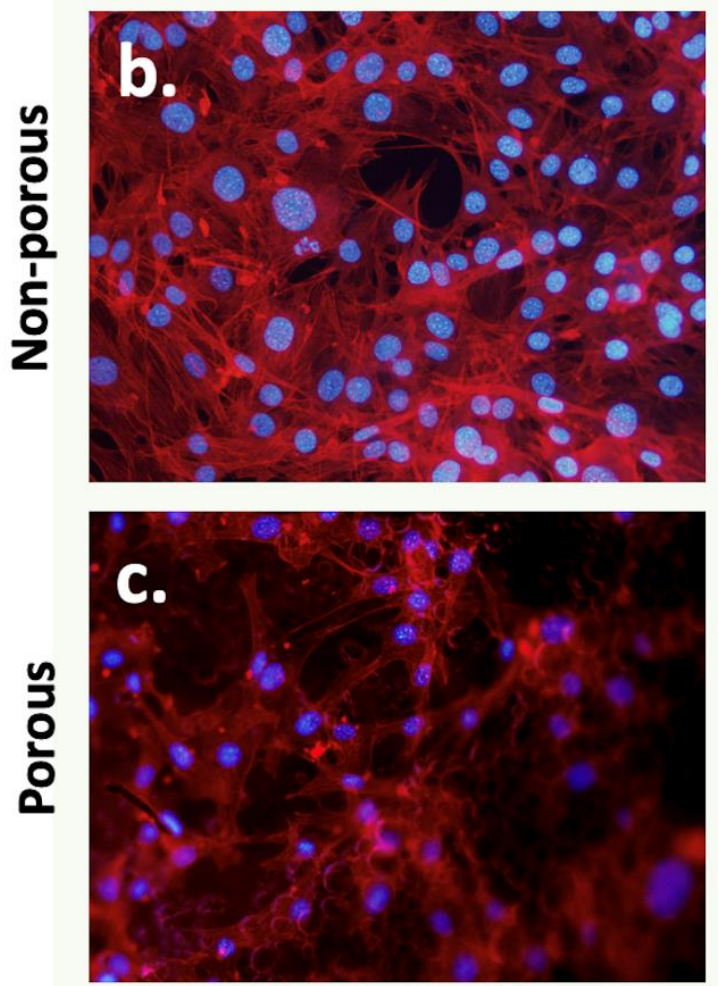

P(VDF-TrFE)/AgNPs
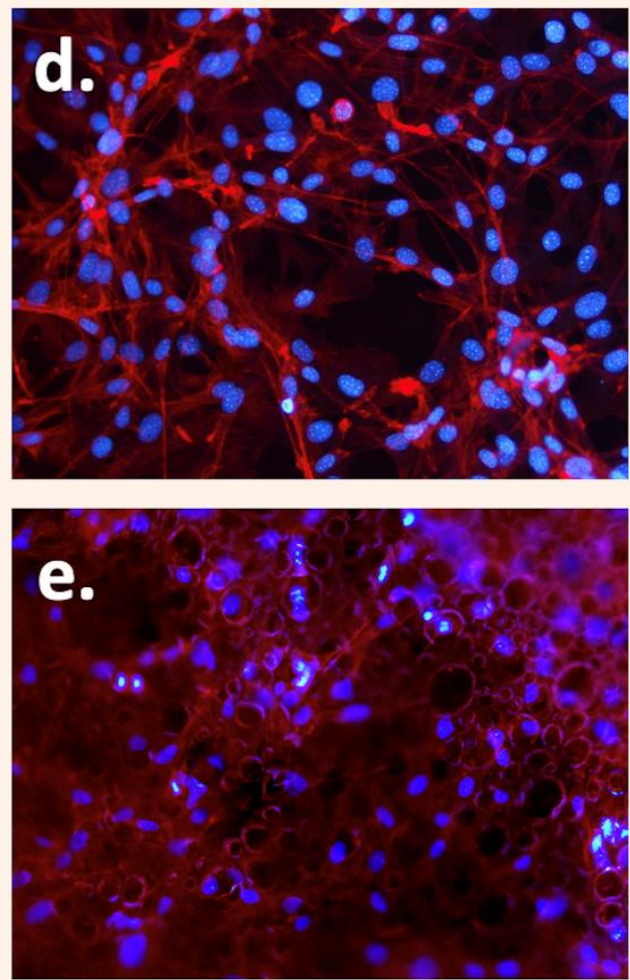

Figure 7. Evaluation of (a) direct cytotoxicity using MTS assay, related to the control where the cells were growth without the material, and fluorescence microscopy analysis of MC3T3E1 cells under (b) nonporous and (c) porous P(VDF-TrFE) films and (d) porous and (e) nonporous $\mathrm{P}(\mathrm{VDF}-\mathrm{TrFE}) / \mathrm{AgNPs}$ films after $24 \mathrm{~h}$. Nuclei were stained blue with DAPI and cytoskeleton stained red with TRITC. Scale bar denote $100 \mu \mathrm{m}$. 
The synergism between the electroactive environments, provided by the piezoelectric scaffolds made of PVDF and its copolymers, PLLA, PLGA, or even silk fibroin and their morphology have been proven beneficial for tissue engineering applications, [54] promoting enhanced proliferation and differentiation of cells [19]. To potentiate these interactions among the cells, physical stimulatory alternatives, such as electrical, mechanical, thermal and magnetic [55] have been applied to potentiate the cells self-renewal, proliferation and differentiation properties [56]. In fact, the physical stimuli used in this study, the mechanical vibration applied to a electroactive PVDF-based materials, originating a mechanoelectrical phenomenon, have also been used to enhance bone regeneration $[44,45,57,58]$. These processes induce a combination of mechanotransduction and electrotransductio phenomena in cells, which is leads to variations in biochemical activities and gene expression in cells [59].

The same strategies have been now used to develop antimicrobial surfaces and to tailor bacterial cell growth and biofilm formation [17]. The use of electroactive materials in combination with antimicrobial compounds has been scarcely explored [60-62] but the synergetic effect has not been convincingly proven under static and dynamic conditions on polymer based composites suitable to be applied in a large variety of surfaces, shapes and morphologies, and therefore, with a large range of possible application environments.

\section{Conclusion}

This work has proven the existence of a synergic effect between the antibacterial effect of AgNPs and the applied piezoelectric stimulus inducing different effects, such as growth inhibition, antifouling, and inhibition of biofilm formation, mainly in Gram-positive bacteria. Gram-negative bacteria E. coli is more resistant to this effect, which is attributed to the different cell membrane structure. In fact, in both types of bacteria, Gram-positive and Gram-negative, it was possible to verify a biocidal effect of AgNPs. Also, in this study, it is found that the morphologies of composites influence bacterial growth without compromising osteoblasts viability.

Considering the obtained results, this antimicrobial strategy could be considered a suitable and promising way of preventing bacterial infections, not only in medical equipment and indwelling 
devices but also in common public surfaces, through the application of these types of composites in the form of coatings. The piezoelectric stimulus is naturally present in PVDFTrFE upon movement, pressure or touch, which would be a perfect trigger for these coating to exert an antibacterial effect upon action. Therefore, this work proves the synergistic effect of a well-known antimicrobial agent and electroactive polymer and highlight the potential of these types of materials to be used as smart coatings that induce antimicrobial activity on demand.

\section{Acknowledgements}

The authors acknowledge the Portuguese Foundation for Science and Technology (FCT) for the research grants SFRH/BD/145455/2019 (EOC) and SFRH/BPD/121464/2016 (MMF), the strategic funding UID/FIS/04650/2020 and UID/BIO/04469/2020 and projects PTDC/BTMMAT/28237/2017 and PTDC/EMD-EMD/28159/2017. The authors thank support within the Bilateral project between the Portuguese Republic and the Republic of Serbia (No. 337-0000227/2019-09/14). Finally, the authors acknowledge funding by Spanish State Research Agency (AEI) and the European Regional Development Fund (ERFD) through the project PID2019-106099RB-C43/AEI/10.13039/501100011033 and from the Basque Government Industry and Education Departments under the ELKARTEK and PIBA (PIBA-2018-06) programs, respectively. 


\section{References:}

[1] E.C.f.D.P.a. Control, Antimicrobial resistance in the EU/EEA (EARS-Net) - Annual Epidemiological Report 2019, in: S. ECDC (Ed.) 2020.

[2] W. Alhazzani, M.H. Møller, Y.M. Arabi, M. Loeb, M.N. Gong, E. Fan, S. Oczkowski, M.M. Levy, L. Derde, A. Dzierba, B. Du, M. Aboodi, H. Wunsch, M. Cecconi, Y. Koh, D.S. Chertow, K. Maitland, F. Alshamsi, E. Belley-Cote, M. Greco, M. Laundy, J.S. Morgan, J. Kesecioglu, A. McGeer, L. Mermel, M.J. Mammen, P.E. Alexander, A. Arrington, J.E. Centofanti, G. Citerio, B. Baw, Z.A. Memish, N. Hammond, F.G. Hayden, L. Evans, A. Rhodes, Surviving Sepsis Campaign: guidelines on the management of critically ill adults with Coronavirus Disease 2019 (COVID-19), Intensive Care Medicine 46(5) (2020) 854-887. [3] D.A. Rasko, V. Sperandio, Anti-virulence strategies to combat bacteria-mediated disease, Nature reviews Drug discovery 9(2) (2010) 117.

[4] I.M. Gould, A.M. Bal, New antibiotic agents in the pipeline and how they can help overcome microbial resistance, Virulence 4(2) (2013) 185-91.

[5] M.M. Fernandes, K. Ivanova, J. Hoyo, S. Perez-Rafael, A. Francesko, T. Tzanov, Nanotransformation of Vancomycin Overcomes the Intrinsic Resistance of Gram-Negative Bacteria, ACS Appl Mater Interfaces 9(17) (2017) 15022-15030.

[6] D. Miranda, V. Sencadas, A. Sanchez-Iglesias, I. Pastoriza-Santos, L.M. Liz-Marzan, J.L. Gomez Ribelles, S. Lanceros-Mendez, Influence of silver nanoparticles concentration on the alpha- to beta-phase transformation and the physical properties of silver nanoparticles doped poly(vinylidene fluoride) nanocomposites, J Nanosci Nanotechnol 9(5) (2009) 2910-6.

[7] L.M. Liz-Marzán, Nanometals: formation and color, Materials today 7(2) (2004) 26-31. [8] H.Y. Lee, H.K. Park, Y.M. Lee, K. Kim, S.B. Park, A practical procedure for producing silver nanocoated fabric and its antibacterial evaluation for biomedical applications, Chemical Communications (28) (2007) 2959-2961.

[9] A.C. Burdușel, O. Gherasim, A.M. Grumezescu, L. Mogoantă, A. Ficai, E. Andronescu, Biomedical Applications of Silver Nanoparticles: An Up-to-Date Overview, Nanomaterials (Basel) 8(9) (2018).

[10] N. Wang, Review of Cellular Mechanotransduction, Journal of physics D: Applied physics 50(23) (2017) 233002.

[11] M.R. Asadi, G. Torkaman, Bacterial Inhibition by Electrical Stimulation, Adv Wound Care (New Rochelle) 3(2) (2014) 91-97.

[12] T.H. Qazi, R. Rai, A.R. Boccaccini, Tissue engineering of electrically responsive tissues using polyaniline based polymers: a review, Biomaterials 35(33) (2014) 9068-9086.

[13] C.M. Bidan, M. Fratzl, A. Coullomb, P. Moreau, A.H. Lombard, I. Wang, M. Balland, T. Boudou, N.M. Dempsey, T. Devillers, Magneto-active substrates for local mechanical stimulation of living cells, Scientific reports 8(1) (2018) 1464.

[14] C. Ribeiro, V. Correia, P. Martins, F.M. Gama, S. Lanceros-Mendez, Proving the suitability of magnetoelectric stimuli for tissue engineering applications, Colloids Surf B Biointerfaces 140 (2016) 430-436.

[15] C. Ribeiro, D.M. Correia, S. Ribeiro, V. Sencadas, G. Botelho, S. Lanceros-Méndez, Piezoelectric poly(vinylidene fluoride) microstructure and poling state in active tissue engineering, Engineering in Life Sciences 15(4) (2015) 351-356.

[16] M.M. Fernandes, E.O. Carvalho, S. Lanceros-Mendez, Electroactive Smart Materials: Novel Tools for Tailoring Bacteria Behavior and Fight Antimicrobial Resistance, Frontiers in Bioengineering and Biotechnology 7(277) (2019) Doi: 10.3389/fbioe.2019.00277.

[17] E.O. Carvalho, M.M. Fernandes, J. Padrao, A. Nicolau, J. Marqués-Marchán, A. Asenjo, F.M. Gama, C. Ribeiro, S. Lanceros-Mendez, Tailoring Bacteria Response by Piezoelectric Stimulation, ACS Applied Materials \& Interfaces 11(30) (2019) 27297-27305. 
[18] C. Ribeiro, C.M. Costa, D.M. Correia, J. Nunes-Pereira, J. Oliveira, P. Martins, R. Gonçalves, V.F. Cardoso, S. Lanceros-Méndez, Electroactive poly (vinylidene fluoride)based structures for advanced applications, Nature protocols 13(4) (2018) 681.

[19] W. Yang, Y. Zhong, C. He, S. Peng, Y. Yang, F. Qi, P. Feng, C. Shuai, Electrostatic selfassembly of pFe3O4 nanoparticles on graphene oxide: A co-dispersed nanosystem reinforces PLLA scaffolds, Journal of Advanced Research 24 (2020) 191-203.

[20] S. Zhang, H. Yan, J.M. Yeh, X. Shi, P. Zhang, Electroactive Composite of FeCl(3) Doped P3HT/PLGA with Adjustable Electrical Conductivity for Potential Application in Neural Tissue Engineering, Macromol Biosci 19(10) (2019) e1900147.

[21] R. Brito-Pereira, D.M. Correia, C. Ribeiro, A. Francesko, I. Etxebarria, L. Pérez-Álvarez, J.L. Vilas, P. Martins, S. Lanceros-Mendez, Silk fibroin-magnetic hybrid composite electrospun fibers for tissue engineering applications, Composites Part B: Engineering 141 (2018) 70-75.

[22] A. Persat, C.D. Nadell, M.K. Kim, F. Ingremeau, A. Siryaporn, K. Drescher, N.S. Wingreen, B.L. Bassler, Z. Gitai, H.A. Stone, The mechanical world of bacteria, Cell 161(5) (2015) 988-997.

[23] M.F. Murphy, T. Edwards, G. Hobbs, J. Shepherd, F. Bezombes, Acoustic vibration can enhance bacterial biofilm formation, J Biosci Bioeng 122(6) (2016) 765-770.

[24] G.N. Bruni, R.A. Weekley, B.J. Dodd, J.M. Kralj, Voltage-gated calcium flux mediates Escherichia coli mechanosensation, Proceedings of the National Academy of Sciences 114(35) (2017) 9445-9450.

[25] C. Ribeiro, C.M. Costa, D.M. Correia, J. Nunes-Pereira, J. Oliveira, P. Martins, R. Gonçalves, V.F. Cardoso, S. Lanceros-Méndez, Electroactive poly(vinylidene fluoride)-based structures for advanced applications, Nature Protocols 13 (2018) 681-704.

[26] S. Davidović, M. Miljković, V. Lazić, D. Jović, B. Jokić, S. Dimitrijević, M. Radetić, Impregnation of cotton fabric with silver nanoparticles synthesized by dextran isolated from bacterial species Leuconostoc mesenteroides T3, Carbohydrate Polymers 131 (2015) 331-336. [27] S. Davidovic, V. Lazic, I. Vukoje, J. Papan, S.P. Anhrenkiel, S. Dimitrijevic, J.M. Nedeljkovic, Dextran coated silver nanoparticles - Chemical sensor for selective cysteine detection, Colloids Surf B Biointerfaces 160 (2017) 184-191.

[28] C.M. Costa, L.C. Rodrigues, V. Sencadas, M.M. Silva, J.G. Rocha, S. Lanceros-Méndez, Effect of degree of porosity on the properties of poly(vinylidene fluoride-trifluorethylene) for Li-ion battery separators, Journal of Membrane Science 407-408 (2012) 193-201.

[29] N. Castro, S. Ribeiro, M.M. Fernandes, C. Ribeiro, V. Cardoso, V. Correia, R. Minguez, S. Lanceros-Mendez, Physically Active Bioreactors for Tissue Engineering Applications, Advanced Biosystems 4(10) (2020) 2000125.

[30] C. Ribeiro, S. Moreira, V. Correia, V. Sencadas, J. Rocha, F. Gama, J. Ribelles, S. Lanceros-Mendez, Enhanced proliferation of pre-osteoblastic cells by dynamic piezoelectric stimulation, Rsc Advances 2(30) (2012) 11504-11509.

[31] K.P. Bankura, D. Maity, M.M.R. Mollick, D. Mondal, B. Bhowmick, M.K. Bain, A. Chakraborty, J. Sarkar, K. Acharya, D. Chattopadhyay, Synthesis, characterization and antimicrobial activity of dextran stabilized silver nanoparticles in aqueous medium, Carbohydrate Polymers 89(4) (2012) 1159-1165.

[32] B. Khodashenas, H.R. Ghorbani, Synthesis of silver nanoparticles with different shapes, Arabian Journal of Chemistry 12(8) (2019) 1823-1838.

[33] L. Carré-Rangel, G. Alonso-Nuñez, H. Espinoza-Gómez, L.Z. Flores-López, Green Synthesis of Silver Nanoparticles: Effect of Dextran Molecular Weight Used as StabilizingReducing Agent, J Nanosci Nanotechnol 15(12) (2015) 9849-55.

[34] A. Francesko, L. Blandón, M. Vázquez, P. Petkova, J. Morató, A. Pfeifer, T. Heinze, E. Mendoza, T. Tzanov, Enzymatic Functionalization of Cork Surface with Antimicrobial 
Hybrid Biopolymer/Silver Nanoparticles, ACS Applied Materials \& Interfaces 7(18) (2015) 9792-9799.

[35] K. Zheng, M.I. Setyawati, D.T. Leong, J. Xie, Antimicrobial silver nanomaterials, Coordination Chemistry Reviews 357 (2018) 1-17.

[36] R. Rebelo, S. Calderon, R. Fangueiro, M. Henriques, S. Carvalho, Influence of oxygen content on the antibacterial effect of Ag-O coatings deposited by magnetron sputtering, Surface and Coatings Technology 305 (2016) 1-10.

[37] D. Howell, B. Behrends, A review of surface roughness in antifouling coatings illustrating the importance of cutoff length, Biofouling 22(6) (2006) 401-410.

[38] D. Fragouli, R. Buonsanti, G. Bertoni, C. Sangregorio, C. Innocenti, A. Falqui, D. Gatteschi, P.D. Cozzoli, A. Athanassiou, R. Cingolani, Dynamical Formation of Spatially Localized Arrays of Aligned Nanowires in Plastic Films with Magnetic Anisotropy, ACS Nano 4(4) (2010) 1873-1878.

[39] V.F. Cardoso, A.C. Lopes, G. Botelho, S. Lanceros-Méndez, Poly(vinylidene fluoridetrifluoroethylene) Porous Films: Tailoring Microstructure and Physical Properties by Solvent Casting Strategies, Soft Materials 13(4) (2015) 243-253.

[40] P. Martins, A.C. Lopes, S. Lanceros-Mendez, Electroactive phases of poly(vinylidene fluoride): Determination, processing and applications, Progress in Polymer Science 39(4) (2014) 683-706.

[41] V. Sencadas, S. Lanceros-Méndez, J. Mano, Thermal characterization of a vinylidene fluoride-trifluorethylene (75-25)(\% mol) copolymer film, Journal of non-crystalline solids 352(50-51) (2006) 5376-5381.

[42] P. Martins, C. Costa, S. Lanceros-Méndez, Nucleation of electroactive -phase poly(vinilidene fluoride) with $\mathrm{CoFe} 2 \mathrm{O} 4$ and $\mathrm{NiFe} 2 \mathrm{O} 4$ nanofillers: A new method for the preparation of multiferroic nanocomposites, Applied Physics A 103 (2010) 233-237.

[43] S. Ray, R.P. Cooney, Chapter 9 - Thermal Degradation of Polymer and Polymer

Composites, in: M. Kutz (Ed.), Handbook of Environmental Degradation of Materials (Third Edition), William Andrew Publishing2018, pp. 185-206.

[44] V. Correia, J.A. Panadero, C. Ribeiro, V. Sencadas, J.G. Rocha, J.L. Gomez Ribelles, S. Lanceros-Méndez, Design and validation of a biomechanical bioreactor for cartilage tissue culture, Biomechanics and Modeling in Mechanobiology 15(2) (2016) 471-478.

[45] C. Ribeiro, J. Pärssinen, V. Sencadas, V. Correia, S. Miettinen, V.P. Hytönen, S.

Lanceros-Méndez, Dynamic piezoelectric stimulation enhances osteogenic differentiation of human adipose stem cells, Journal of Biomedical Materials Research Part A 103(6) (2015) 2172-2175.

[46] A. Mai-Prochnow, M. Clauson, J. Hong, A.B. Murphy, Gram positive and Gram negative bacteria differ in their sensitivity to cold plasma, Scientific reports 6 (2016) 38610. [47] Y. Yuan, M.P. Hays, P.R. Hardwidge, J.Y. Kim, - Surface characteristics influencing bacterial adhesion to polymeric substrates, - RSC Advances (- 23) - 14254.

[48] D. Perera-Costa, J.M. Bruque, M.L. González-Martín, A.C. Gómez-García, V. Vadillo-

Rodríguez, Studying the influence of surface topography on bacterial adhesion using spatially organized microtopographic surface patterns, Langmuir 30(16) (2014) 4633-41.

[49] H.H. Tuson, D.B. Weibel, Bacteria-surface interactions, Soft Matter 9(18) (2013) 43684380.

[50] V.F. Cardoso, D.M. Correia, C. Ribeiro, M.M. Fernandes, S. Lanceros-Méndez, Fluorinated Polymers as Smart Materials for Advanced Biomedical Applications, Polymers 10(2) (2018) 161.

[51] V. Sencadas, C. Ribeiro, J. Nunes-Pereira, V. Correia, S. Lanceros-Méndez, Fiber average size and distribution dependence on the electrospinning parameters of poly(vinylidene fluoride-trifluoroethylene) membranes for biomedical applications, Applied Physics A 109(3) (2012) 685-691. 
[52] C. Liao, Y. Li, S.C. Tjong, Bactericidal and Cytotoxic Properties of Silver Nanoparticles, Int J Mol Sci 20(2) (2019).

[53] W.S. Williams, L. Breger, Piezoelectricity in tendon and bone, Journal of Biomechanics 8(6) (1975) 407-413.

[54] C. Ribeiro, V. Sencadas, D.M. Correia, S. Lanceros-Méndez, Piezoelectric polymers as biomaterials for tissue engineering applications, Colloids and Surfaces B: Biointerfaces 136 (2015) 46-55.

[55] A.R. Amini, C.T. Laurencin, S.P. Nukavarapu, Bone tissue engineering: recent advances and challenges, Critical reviews in biomedical engineering 40(5) (2012) 363-408.

[56] M. Votteler, P.J. Kluger, H. Walles, K. Schenke-Layland, Stem Cell Microenvironments - Unveiling the Secret of How Stem Cell Fate is Defined, Macromolecular Bioscience 10(11) (2010) 1302-1315.

[57] C. Ribeiro, D.M. Correia, I. Rodrigues, L. Guardão, S. Guimarães, R. Soares, S. Lanceros-Méndez, In vivo demonstration of the suitability of piezoelectric stimuli for bone reparation, Materials Letters 209 (2017) 118-121.

[58] M.M. Fernandes, D.M. Correia, C. Ribeiro, N. Castro, V. Correia, S. Lanceros-Mendez, Bioinspired three-dimensional magneto-active scaffolds for bone tissue engineering, ACS Applied Materials \& Interfaces 10.1021/acsami.9b14001 (2019).

[59] M. Mofrad, R. Kamm, Cellular mechanotransduction: Diverse perspectives from molecules to tissues, 2009.

[60] G. Tan, S. Wang, Y. Zhu, L. Zhou, P. Yu, X. Wang, T. He, J. Chen, C. Mao, C. Ning, Surface-Selective Preferential Production of Reactive Oxygen Species on Piezoelectric Ceramics for Bacterial Killing, ACS Applied Materials \& Interfaces 8(37) (2016) 2430624309.

[61] J. Nunes-Pereira, P. Costa, L. Fernandes, E.O. Carvalho, M.M. Fernandes, S.A.C. Carabineiro, J.G. Buijnsters, C.R. Tubio, S. Lanceros-Mendez, Antimicrobial and Antibiofilm Properties of Fluorinated Polymers with Embedded Functionalized Nanodiamonds, ACS Applied Polymer Materials 2(11) (2020) 5014-5024.

[62] C. Shuai, G. Liu, Y. Yang, F. Qi, S. Peng, W. Yang, C. He, G. Wang, G. Qian, A strawberry-like Ag-decorated barium titanate enhances piezoelectric and antibacterial activities of polymer scaffold, Nano Energy 74 (2020) 104825. 